\title{
Ghana National Community Health Planning and Services (CHPS) policy; gaps between policy and implementation, the need for policy review to address specific gaps
}

\author{
Ahotovi Thomas Ahoto ${ }^{1,}{ }^{*}$, Lok Mani Giri ${ }^{2}$ and Suyasha Koirala ${ }^{2}$ \\ School of Management Jiangsu University, 301 Xuefu Road, Zhenjiang, 212013, China \\ Master of Science in Public Health (MScPH) The University of Southern Denmark (SDU), Esbjerg, Denmark
}

Magna Scientia Advanced Biology and Pharmacy, 2021, 02(01), 026-034

Publication history: Received on 06 March 2021; revised on 16 April 2021; accepted on 19 April 2021

Article DOI: https://doi.org/10.30574/msabp.2021.2.1.0013

\begin{abstract}
The study examines gaps in primary health policy designed to enable Ghana to achieve universal access to health. The policy has existed for over 15 years with remarkable achievements, but data shows gaps between the procedure and what is going on. The researchers use a qualitative technique to explore the gap by focusing on persons directly involved in policy implementation as participants. Three main japs were identified, insufficient collaboration between community health officers and community leaders, favoritism in promoting CHOs, and inadequate provision of medical consumables and tools to CHPS-compounds as stated by the policy. The study concluded with the call for a review of the procedures and examining of the outlined gaps
\end{abstract}

Keywords: Community Health; Policy Review; CHPS-Ghana; Community Health; Bridging the Health Gap

\section{Introduction}

Over the years, the Ghana health service and the ministry of health tested several strategies to achieve universal health coverage (1). In 1977 Ghana adopted Community Clinic Attendants and Traditional Birth Attendants to get health delivery to the hard-to-reach communities even before the Alma Ata Declaration in 1978 of 'Health for All by the year 2000' with a focus primary healthcare. Ghana piloted the Community-Based Health Planning and Services (CHPS) lesson from Bangladesh in three sub-districts of Navrongo in the Upper West region in 1994 (2). The focus of CHPS was to reduce inequalities in health delivery through the mobilization of resources from the community and the health system. The policy was well developed on the principles of Community participation, empowerment, ownership, gender considerations, and volunteerism, focusing on community health need to determine the package of CHPS services (3).

Measuring the policy successes in achieving universal access to healthcare, one can state that some accomplishments have been steered over the fifteen years of implementation. The following health indicators attested to the achievements; Under Five Mortality decreasing from 99.4 in the year 2000 to 46.2 in 100000 live births in 2019, Infant Mortality fell from 64. 1 in 2000 to 33.9 2019, Life Expectancy increasing from 57.0 in 2000 to 63. 78 in 2018, the Total Fertility Rate is decreasing from 4.8 in 2000 to 3.8 in 2018 (1).

\footnotetext{
${ }^{*}$ Corresponding author: Ahotovi Thomas Ahoto

School of Management Jiangsu University, 301 Xuefu Road, Zhenjiang, 212013, China.
} 

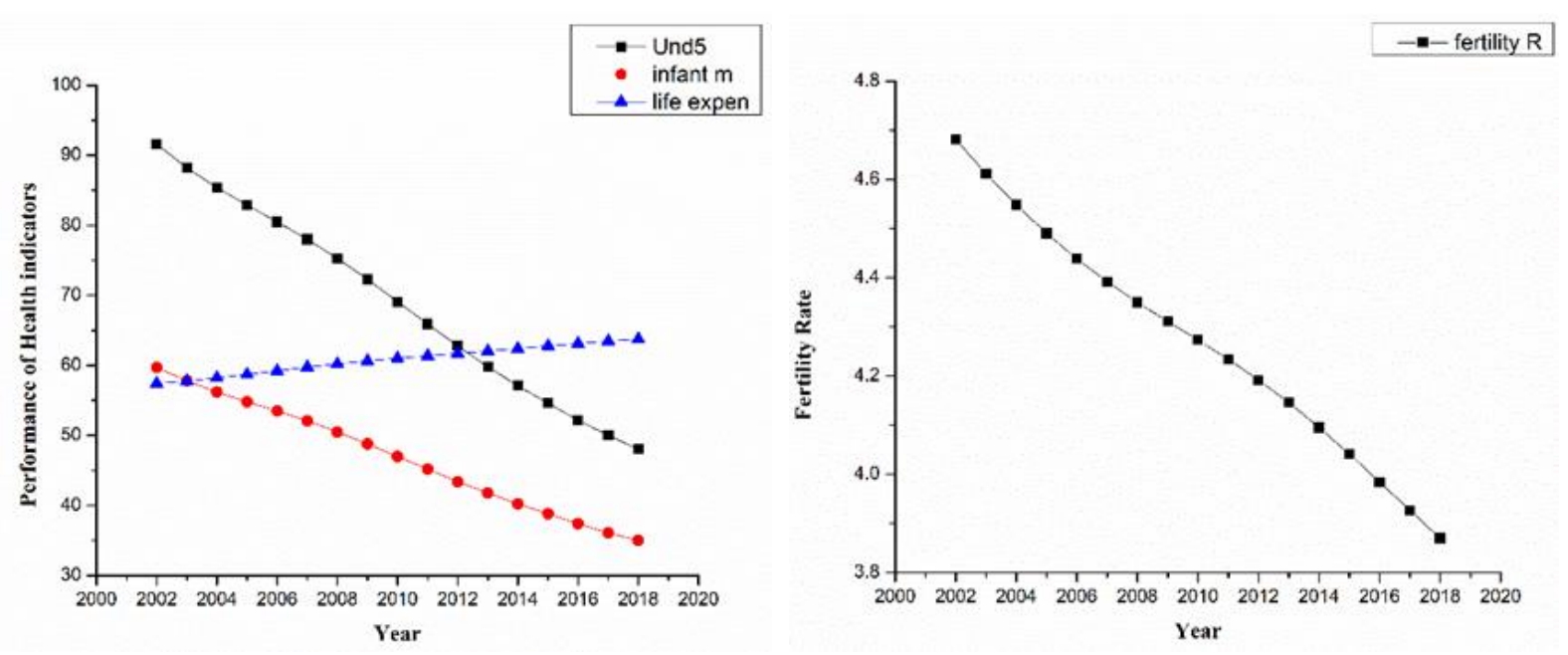

Figure 1 Graphical demonstration of CHPS-Policy Successes

Though there has been high coverage of CHPS compounds in most communities as defined by the policy, studies show policy gaps as some fundamental principles on which the policy was design seemed to be ignored (3). The community involvement aspect, community-based resource mobilization, and community volunteerism are hardly seen in the actual CHPS projects (4). The community gaps are slowly turning the CHPS compounds into treatment centers that mostly lack the essential medical supply, buildings dilapidated, and in some cases maned by an inadequate number of Community Health Officers (CHO). Another aspect of the policy being ignored is the nonpayment of attention to community specifications which take into account the common diseases in the community, resource capacity, and other social structures of the community. Again the designed motivation packages established for community health officers who work in the rural areas seemed to be distributed unevenly (5).

Nonetheless, one cannot deny the policy's implementation brought some improvements in health delivery. Health statistics could have been enhanced than what it is currently, and resource challenges faced by the CHPS-compound would have been minimized if the above gaps were worked on (6). There is a need to review the policy to match the original principles and develop new ways to derive many benefits. If communities were involved as planned, there is the likelihood of resource generating from the community members instead of depending on the central government, which hardly provides the needful. Similarly, some specific communities' endemic disease conditions could have been handled better than their current state (7).

\subsection{Conceptual framework}

The CHPS policy was conceptualized using the Health Policy Triangle engineered in the 1990s; the policy triangle created the framework that enables policy developers to capture and direct policies toward the targeted communities (8). In the CHPS policy, the context is toward universal access to health and reduce inequalities in health delivery.

Universal healthcare coverage was to be attained through primary healthcare, community-specified disease handling, and the mobilization of community support for health delivery (9). The key players, Ministry of Health, Ghana Health Service, and opinion leaders in various communities were equally factored in the policy as actors. Though all the policy triangle elements concerning CHPS policy are functioning effectively in the policy. CHPS policy is operating without opinion leaders' participation, and it denies the revenue that could have been generated from that level (2). Many CHPS compounds depend on the central government and funds generated from the National Health Insurance Scheme, which is not enough to meet the medical demands. As of 2016, there were 4,700 CHPS compounds built, with many of them operating, showing how some actors (ministry of health and Ghana health service) were adhering to the policy's sustenance without giving much attention to the involvement of the community (1). 


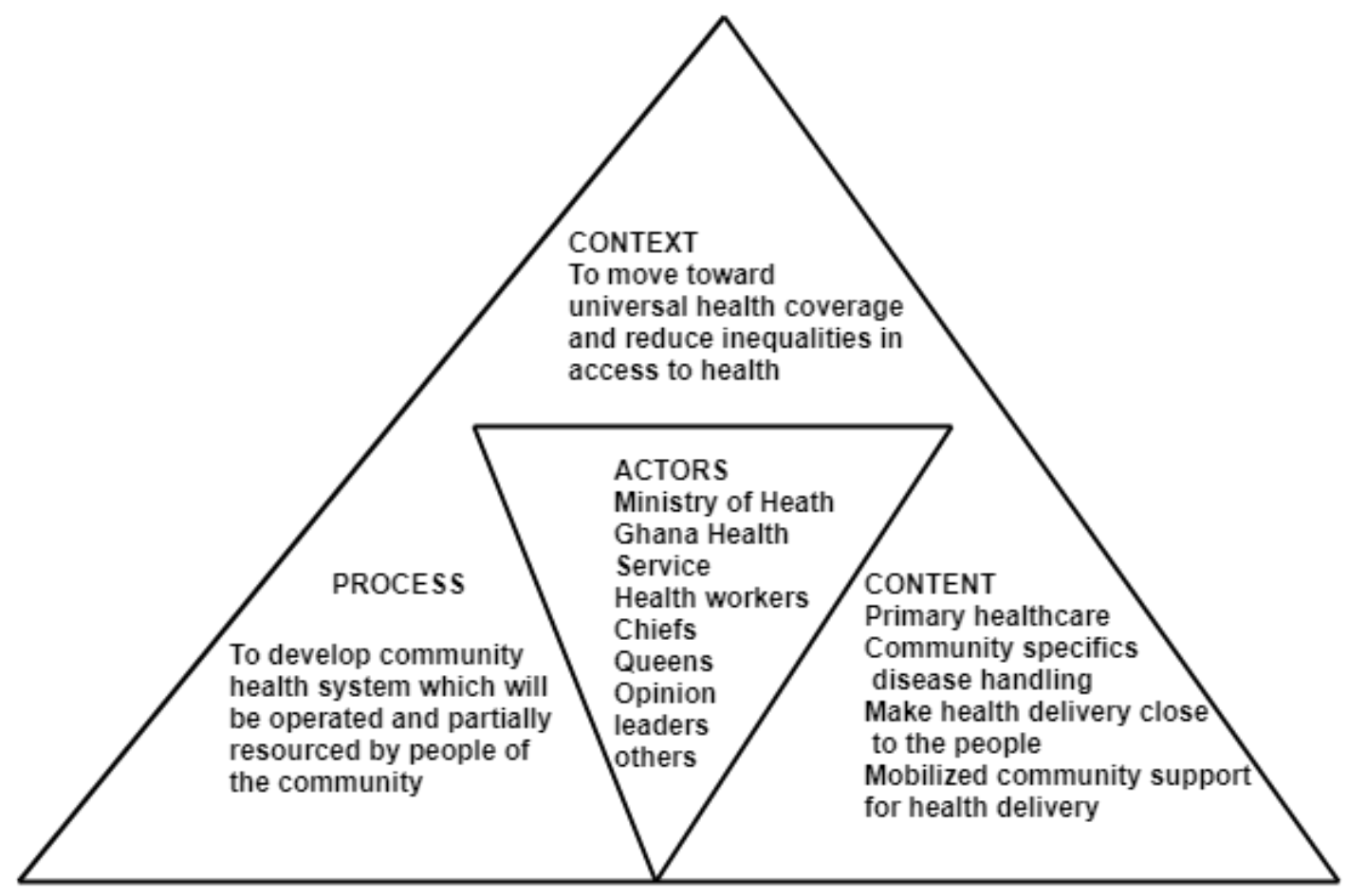

Figure 2 Health policy triangle

\section{Methodology}

A qualitative exploratory research approach was adopted, focusing on exploring three main gaps between the written CHPS policy and various communities where CHPS compounds were functioning. Using focus group discussion, the researchers examined three gaps identified by reviewing data from the ministry of health, Ghana health service, publications from researchers and other key bodies, and media communication about CHPS policy over the 15years of policy existence. Using exploratory research helped us to investigate and provide deeper explanations to the identified gaps. These gaps are 1. Inadequate participation of opinion leaders in the communities as stated by the policy and its implications. 2 Lack of neutrality in awarding promotions to community health offices as stated in the policy and its effect on job performance. 3. Insufficient and late supply of medical consumables and tools to the CHP-compound and its impact on health delivery.

\subsection{Setting}

The study was conducted in the North Tongu District in the Volta region of Ghana. The district is located along the Volta River and has Battor-Dugame as its capital. Apart from the Battor district hospital, CHPS-compounds are the places of treatment for the dwellers. Occupants of the districts are ethnic Ewes, with farming and fishing as their primary occupations. Jumping is the most vibrant commercial city in the community. Dedukope, Dove, Alabonu, Adafe, Yayrafe Tsidzenu, and Ayimagonu CHPS-compounds are few places with a functioning CHPS-compound in the district, there are other health facilities in the district, but the study focused on CHPS policy; therefore, only people from the above communities were considered for participation.

\subsection{Ethical Review}

The study does not required Ethical clearance as it is within the domain of social science research and does not involve any vulnerable groups.

\subsection{Selection of Participants}

Two groups of participants were selected based on the gaps identified; community health officers (CHOs) and opinion leaders. Per the gaps identified in the policy implementation, these two groups are at the center of the issues. 


\subsection{Selection Criteria}

Opinion leaders are classified as religious leaders, chiefs, queen mothers, head teachers, employers, and good standing people in business within the community. CHOs are made up of qualified CHOs with certificates recognized by Ghana health service, work and stay within the community over a year and be punctual at work.

Participants who meet the above criteria were made to list the challenges or gaps they have identified or experienced when comparing the initial CHPS concept and the 2014 policy document to the actual implementation. The majority whose answers partially or fully fell in line with the gaps the researchers established were selected. A total of 28 opinion leaders and 33 CHOs were chosen to participate in the study. But the numbers were reduced from 21 and 27, respectively, because some participants did not turn up for the discussion.

\subsection{Data Collection}

Participants were divided into four groups (two groups for CHOs and two groups for opinion leaders), research assistants experienced in data collection, hold BSc and MSc in health-related programs, and fluent in both the local dialect and English language were trained to assist in the data collection. With the assistant's help, the researcher moderated the discussion to enable the participants' active participation. CHOs communicated in the English language while the opinion leader used both languages. The conversations were audio-recorded using two sets of recorders. The discussions were held in a church building with only participants and the research team present.

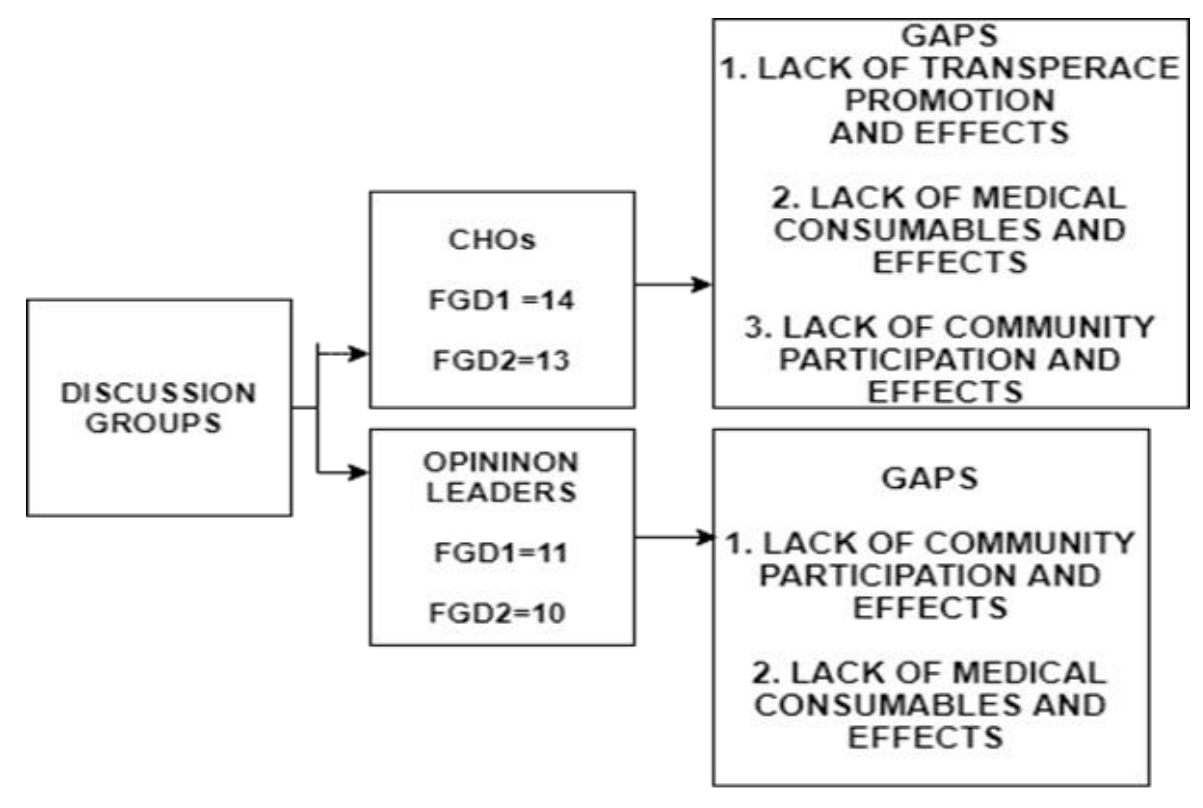

Figure 3 Focus Group Structure

From figure 3. Two main focus groups were developed, community health officers groups were again divided into two sub-groups, with 14 members and 13 members. They were made to discuss the identified gaps. Opinion leaders had two groups, with the first having 11 members and the other having ten members. Gaps discussed by them were community participation and its effects and issues that have to do with medical consumables and their consequences; each discussion took 46 to 59 minutes, and member checking was done by asking some participants to affirm what was recorded.

\subsection{Analysis}

Audio recordings were transcribed verbatim, and Manual thematic analysis was done by assigning code to the various data; since the themes were already developed based on the implementation gaps, emerging patterns of themes from various focus group discussions were properly aligned to the right themes. Further reviews of the themes alignment were done to check all important patterns from the captured data. An independent coder was employed who compared notes with the other two researchers. Misunderstanding resulting from different views on themes alignment was addressed throughout the process. Data saturation was reached when all the researchers could not develop any new themes from the data aligned to the reference themes. Findings were presented and backed with quotations from the participants. 


\subsection{Reflexivity}

The research team holds the following qualifications, Ph.D., MSc, and BSc. Candidate. All the researchers were from the fields of public health, social medicine, and health policy. Though research assistants were fluent in the local dialects, there were not from the same communities as researchers; therefore they were no familiarities between the two parties. The discussions were friendly, and each participant was encouraged to express his or her views.

\subsection{Rigor and Trustworthiness}

To ensure the credibility of findings and academic rigor, reflexivity and bracketing were emphasized with field notes and methodological notes produced. Trustworthiness was given the needed attention by organizing three separate meetings with participants. Promotion of neutrality and subduing the imposition of preconceived ideas was enhanced. All transcripts were treated equally until saturation was achieved. Attention was paid to field notes and the details of CHPS establishment notes, and the policy document of 2014.

\subsection{Dependability}

Dependability was enhanced by selecting participants who met the criteria, reviewing and comparing the research procedure with other studies procedures. Conformability was established between field notes coding notes, written transcripts, audiotaped interviews, and the CHPS policy document of 2014 and the 1994 initial briefings about the policy to achieve consistency and reader comprehension.

\section{Results}

\subsection{Demography}

A total of 46 participants were selected from seven CHPS-zones in the Volta region of Ghana, out of which 25 were Community Health Officers, and the rest 21 were community leaders. Health workers were aged from $27-46$ years, while community leaders aged 34-61. Three of the CHOs were males, and 22 were females, while only two community leaders were female. Six of the CHOs hold a certificate in healthcare, and 19 hold diplomas in nursing and midwifery. Only two persons among the community leaders hold a first degree. The rest hold post-secondary certificates, secondary school certificates or had no forms of formal education.

Know about 1994 CHPS- implementation and 2014 CHPS policy among participants

Table 1 Background of Participants

\begin{tabular}{|l|l|l|l|l|l|}
\hline $\begin{array}{l}\text { Participant } \\
\text { Groups }\end{array}$ & Numbers & Aged & Description & Sex & EDUCATION \\
\hline $\begin{array}{l}\text { Community } \\
\text { Health Officers }\end{array}$ & 25 & $27-46$ & $\begin{array}{l}\text { Community Health } \\
\text { Nurses } \\
\text { Midwives } \\
\text { Health Assistants }\end{array}$ & $\begin{array}{l}\text { Males 3 } \\
\text { Females 22 }\end{array}$ & $\begin{array}{l}\text { Diploma and certificate } \\
\text { holder }\end{array}$ \\
\hline $\begin{array}{l}\text { Community } \\
\text { Leaders }\end{array}$ & 21 & $34-61$ & $\begin{array}{l}\text { Chiefs, Religious } \\
\text { Leaders, Youth Group } \\
\text { Leaders, Community } \\
\text { Elders, Head Masters, } \\
\text { And Chief Famers }\end{array}$ & $\begin{array}{l}\text { Males 19 } \\
\text { Females 2 }\end{array}$ & $\begin{array}{l}\text { Degree, diploma, } \\
\text { Post-secondary } \\
\text { Secondary-school and } \\
\text { below }\end{array}$ \\
\hline
\end{tabular}


Table 2 Themes and Sub-Themes

\begin{tabular}{|l|l|}
\hline Main Themes & $\begin{array}{l}\text { Sub-Themes } \\
\text { Codes }\end{array}$ \\
\hline $\begin{array}{l}\text { Knowledge about 1994 CHPS implementation and } \\
\text { 2014 CHPS policy }\end{array}$ & $\begin{array}{l}\text { Lack of public awareness about CHPS policy } \\
\text { Misunderstanding of the policy } \\
\text { Insufficient knowledge about the policy }\end{array}$ \\
\hline Lack of community engagement & $\begin{array}{l}\text { Totally or partially ignored community leaders. } \\
\text { Poor cooperation from the community leaders } \\
\text { Effects of Lack of community leaders engagement }\end{array}$ \\
\hline $\begin{array}{l}\text { Lack of adherence to promotion for community } \\
\text { health officers as presented by the policy }\end{array}$ & $\begin{array}{l}\text { Biased promotion } \\
\text { Ignorance of the policy planed promotion design } \\
\text { Effects of poor adherence to promotion designed. }\end{array}$ \\
\hline & $\begin{array}{l}\text { Delay in the medical supply } \\
\text { Lack of essential working tools } \\
\text { Insufficient funding for extra needs }\end{array}$ \\
\hline
\end{tabular}

\subsubsection{Knowledge about CHPS program and policy}

The researchers tried and captured the participants' understanding of the policy. CHOs demonstrated some levels of knowledge of the policy as they stated there is the need for community support and health delivery to be accessible for the communities' people. Community leaders see the CHPS compounds built for them as a fulfillment of pledges by politicians. They made no mention of the policy, though they are aware of the need for their participation.

"CHPS policy is a plan to enable us to provide people in these communities with basic care; they are not to pay for treatment, we were trained to engage the community in our activities, and they were also supposed to support us with some basic needs, I have not read the policy, but I know what I am supposed to do" CHO13.

"The politicians pledged to build this small hospital here, and they delivered it when they won power; all told we CHOs here are to treat us without taking money; they have brought health care closer to us. I know nothing about policy document" CL5

\subsubsection{Lack of community engagement}

As stated of the CHP-policy, the communities are to be active in all health programs and provide some resources to health delivery, and we evaluate this important policy directive by checking the levels of engagement;

Levels of Community Participation; from the FGD, it emerged that community leaders were involved at the initial stages of CHPS policy implementation but were ignored after the project's commencement. They mainly provide lands for buildings and decide on a location for siting the projects.

"We leaders of the communities were called upon to provide land for the building and we did, during the opening of the compound we were there as invited by the DCE, since then no one tells us anything about the clinic our families only complain to us of any problem they face when they come for treatment" CL22

"I am aware that they have to hold periodical discussions with us, so we can also give them some inputs; some of us can contribute and paint the building for them, but they think we are not educated or we do not have any ideas about health, they do not call us for any discussion" CL5.

"We attended their programs when they invited us to give a talk. We do not hold official discussions with them because we have a lot of work to do daily, again leadership in the communities is not well defined; therefore, we hardly know who to contact first" CHO5.

Poor Cooperation From The Community Leaders; Community Health Officers expressed insufficient cooperation from people in the communities, and they stated that people in the communities give excuses anytime they organized health 
programs for them "The community engagement is not only for decision making, we sometimes invite the women for health education, but they hardly turn up, when we questioned them they gave many reasons including their job as an obstacle preventing them from coming" CHO12.

Effects of weak community engagement: per the policy directive, resources for the implementation were supposed to be partially mobilized from the community, but it seemed this has failed as the communities mainly provide plots of land for the build, which ends their contribution. "Because the community leaders hardly meet with us, we find it difficult to approach them for any support. Sometimes when we even get closer to them, their partners say an unpleasant thing about us, truth be told we only depend on government for our resources need." CHO 7

\subsubsection{Biased in $\mathrm{CHO}$ promotion;}

The policy stated that CHOs who work in deprived communities staff could be promoted in three years of work and have access to study leave to further their education than their collogues workers who serve in developed cities. Some CHOs complained this policy is not being implemented fairly.

Lack of adherence to promotion to structure in the policy; Some CHOs expressed disappointment due to how they were ignored when others were being promoted "Not all of us have been promoted as stated, though that was the motivation that made us to come to these communities most of us were denied. The authorities were biased as to whom to be promoted" CHO 23 "I know people who have to serve in this and other communities for less than three years, yet they are on study leave, this is unethical" CHO 25

Demotivation; A worried CHOs expressed how they are losing interest in their job. "Non-adherence to the stated promotion plan hurt us. We plan our future based on the promotion, and sometimes they tell you there is no one to take over from us, so we cannot leave for study leave. I feel unhappy at work when I think about this" CHO19.

\subsubsection{Medical consumables and tools supply gaps}

Comparing the policy document to what is happening in CHP-Compounds, we identified the gap of insufficient supply of medical consumables, Lack of working tools, and inadequate funding for carrying out any activities stated by the policy.

Delay in medical supply; CHOs unanimously stated that they are faced with challenges in getting medical consumables and tools materials. "The district health directorate was to supply us with drugs and other things, but sometimes most drugs get finished without supply to replace them. Our requests hardly come on time" CHO4. "Sometimes community people do not have the desire to seek for health from CHPS-Compound because we cannot meet their basic medical needs and they have to go to the drug-store to buy them, and this is affecting their confidence in us" CHO7.

Lack of Basic Tools at CHPS-Compound; To the CHOs, getting tools to work with can be challenging. "The district directorate of health is to provide us with basic items like gloves. As a midwife, I have to get my own gloves; else I have to work without gloves. I feel the district health directorate forget about us. Even chargeable lamp in times of light out they refused to provide it for us" CHO6.

Lack of funding for other needs; Lack of regular interaction between CHOs and community leader is depriving the support the community can offer to the CHPS-program "We were supposed to get funding from government and the community, but for now only government gives us funding. We need money to buy some basic items, but we hardly generate the needed amount; people in the communities are mainly farmers, and I do not think they have enough to give us that support" CHO10.

Maintenance gaps the CHPS compound "builds have not to been painted for years now; the roof leaks anytime it rains. Most of the electrical gadgets are faulty. We informed authorities about this, but we hardly get any response. The fans are not working the places can be hot in the afternoon to the extent that we have to work under three outside" CHO8.

\section{Discussion}

Health policies remained the fundamental guidelines for health delivery. The Health Policy Triangle has been used globally for designing policies by inculcating content, context, and process to focus on actors who are at the center of every policy (8). Ghana Community Health Planning and Services (CHPS) policy implemented in 1999 well fit into the policy triangles as all aspects of the triangle were captured. Currently, there is a need for policy review as there are gaps between the 1999 initial policy plan, the 2014 policy document, and the actual policy implemented. Lack of adherence 
to the policy document lowers the gains made from the procedure (1). The study evaluates the gaps between the policy document and what is happening on the ground in three segments. The first gap is weak community engagement. Though the policy stated the CHPS project must focus on community participation, the study results revealed that Community Health Officers hardly engaged the community leaders; this is similar to the finding by (7). The above gap has resulted in poor resource mobilization from the community levels. It has equally forced CHPS-compound operators to depend on the government for most of their needs which the CHOs stated were not provided on time. The study by (1) also established similar findings and called for a policy review.

The second gap identified is the lack of adherence to the structured promotion for CHOs. The participants stated how biased authorities were when it came to awarding career promotions and study leaves. According to (4), some CHOs were left in the rural communities without adequate upgrades, as stated in the CHPS-policy. In line with the above argument, the study has also established that some CHOs are losing interest in the job as they felt ignored when it comes to promotional issues. The negative feeling is likely to affect their delivery at work. It must be stated that these CHOs serve in very rural communities, with early promotions being their main motivations as stated in the policy document, and refusal to adhere to this may lead to others refusing to work in such rural communities (7).

The final gap evaluated is the gap in medical consumables and tools supply; this gap exposed partial deviation from the 2014 policy document. Though it was stated that the government and the community would provide essential medical equipment and specific drugs, the fact expressed by the CHOs shows that only the government is providing them with these resources. Even what the government offers is inadequate, with delayed delivery being rampant. Kweku et al. ( 2020) stated that most CHPS-compounds struggle to fulfill their obligation since resources hardly get to them. According to the CHOs, this gap made communities' peoples overlook them and seek health at other places, which devalue their importance to the community.

\subsection{Limitation}

The study's findings cannot measure the policy's performance at the national level since only a few participants were involved in the research, and participants were purposively selected. The geographical coverages of the study are also limited in scope.

\subsection{Recommendation}

Based on our findings, there is a need for a review of the policy to enforce some policy directives. Efforts must be made to engage the community leaders as it can help to mobilized resources for the CHPS projects. We recommend further studies on the topic.

\section{Conclusion}

There is no doubt that the CHPS policy is one of the most successful policies that has survived for over $15 y e a r s$ and has not been affected by governments' change over the ages. Though its success cannot be overlooked, there is a need for review as the gap between the policy and implementation negatively impacts the actual benefits. There is the need to relook the three gaps outlined in the study even if general reviews are not carried out.

\section{Compliance with ethical standards}

\section{Acknowledgments}

Authors acknowledged the effort of all participants during data collection and analysis.

\section{Disclosure of conflict of interest}

Authors have no conflicting interest throughout the study.

\section{References}

[1] Yeboah B. PROGRESS OF COMMUNITY-BASED HEALTH PLANNING AND SERVICES IN. 2020;(January).

[2] Draft W, Validation FOR. National Community Health Planning and Services ( CHPS ) Policy. 2014;(November).

[3] Kweku M, Id HA, Awolu A, Adjuik M, Id AA, Manu E, et al. Community-Based Health Planning and Services Plus 
programme in Ghana : A qualitative study with stakeholders in two Systems Learning Districts on improving the implementation of primary health care. 2020;1-24. Available from: http://dx.doi.org/10.1371/journal.pone.0226808

[4] Wiru K, Kumi-kyereme A, Mahama EN, Amenga-etego S, Owusu-agyei S. Utilization of community-based health planning and services compounds in the Kintampo North Municipality: a cross- sectional descriptive correlational study. 2017;1-11.

[5] Nsarko CN, Consultant L. Strengthening Community Health Systems in Ghana Evidence to Policy. 2014;

[6] Adongo PB, Tapsoba P, Phillips JF, Tabong PT, Stone A, Kuffour E, et al. The role of community-based health planning and services strategy in involving males in the provision of family planning services : a qualitative study in Southern Ghana. Reprod Health [Internet]. 2013;10(1):1. Available from: Reproductive Health

[7] Johnson FA, Frempong-ainguah F, Matthews Z, Andrew J. Evaluating the Impact of the Community- Based Health Planning and Services Initiative on Uptake of Skilled Birth Care in Ghana. 2015;1-18.

[8] Carey R, Caraher M, Lawrence M, Friel S. Opportunities and challenges in developing a whole-of-government national food and nutrition policy : lessons from Australia's National Food Plan Opportunities and challenges in developing a whole-of- government national food and nutrition policy : less. 2015;(October).

[9] Kruse CS, Williams K, Bohls J, Shamsi W. Telemedicine and health policy: A systematic review. Heal Policy Technol [Internet]. 2020; Available from: https://doi.org/10.1016/j.hlpt.2020.10.006 